\title{
A rapid assessment of the quality of neonatal healthcare in Kilimanjaro region, northeast Tanzania
}

\author{
Bernard Mbwele ${ }^{1 *}$, Elizabeth Reddy ${ }^{2}$ and Hugh Reyburn ${ }^{3}$
}

\begin{abstract}
Background: While child mortality is declining in Africa there has been no evidence of a comparable reduction in neonatal mortality. The quality of inpatient neonatal care is likely a contributing factor but data from resource limited settings are few. The objective of this study was to assess the quality of neonatal care in the district hospitals of the Kilimanjaro region of Tanzania.

Methods: Clinical records were reviewed for ill or premature neonates admitted to 13 inpatient health facilities in the Kilimanjaro region; staffing and equipment levels were also assessed.

Results: Among the 82 neonates reviewed, key health information was missing from a substantial proportion of records: on maternal antenatal cards, blood group was recorded for 52 (63.4\%) mothers, Rhesus (Rh) factor for 39 (47.6\%), VDRL for 59 (71.9\%) and HIV status for 77 (93.1\%). From neonatal clinical records, heart rate was recorded for3 (3.7\%) neonates, respiratory rate in 14, (17.1\%) and temperature in 33 (40.2\%). None of 13 facilities had a functioning premature unit despite calculated gestational age $<36$ weeks in $45.6 \%$ of evaluated neonates. Intravenous fluids and oxygen were available in 9 out of 13 of facilities, while antibiotics and essential basic equipment were available in more than two thirds. Medication dosing errors were common; under-dosage for ampicillin, gentamicin and cloxacillin was found in $44.0 \%, 37.9 \%$ and $50 \%$ of cases, respectively, while over-dosage was found in 20.0\%, 24.2\% and 19.9\%, respectively. Physician or assistant physician staffing levels by the WHO indicator levels (WISN) were generally low.

Conclusion: Key aspects of neonatal care were found to be poorly documented or incorrectly implemented in this appraisal of neonatal care in Kilimanjaro. Efforts towards quality assurance and enhanced motivation of staff may improve outcomes for this vulnerable group.
\end{abstract}

\section{Background}

The World Health Organization estimates that 4 million children under 1 month of age die each year [1,2] and more than $90 \%$ of these deaths occur in developing countries $[3,4]$. Neonatal mortality rates have remained high despite a decline of infant mortality rates [5]. The highest neonatal mortality rates are documented in subSaharan Africa [1,6-9]. Tanzania is among the five countries in sub-Saharan Africa recording the highest neonatal mortality rates, $[8,10]$ with birth asphyxia, prematurity and infection as prime causes, all of which are preventable [11].

\footnotetext{
* Correspondence: benmbwele@gmail.com

${ }^{1}$ Kilimanjaro Clinical Research Institute, P.O Box 2236, Moshi, Tanzania

Full list of author information is available at the end of the article
}

The relative lack of progress in reducing neonatal mortality may be at least in part due to a gap between national or international standards of good care of neonates and the actual delivery of care health facilities [12-14]. However, the lack of quantitative and qualitative data, including an absence of stable and accurate vital registration systems [15-18] and retrieval systems, constitute constraints in making a useful judgment of the quality of care $[10,19]$.

A study conducted in 2002 in the Kilimanjaro region of Tanzania found that only one-third of all inpatientdeaths were properly documented in the case notes, and the cause of death could only be determined in $38 \%$ of the these [20]. Most of the neonatal deaths in northern Tanzania are preventable, [21,22] and an audit of records 
in a Dar es Salaam teaching hospital showed quality neonatal care was often suboptimal even within the context of available resources [23].

This study aimed to provide an overview of the quality of neonatal health care in district hospitals and health centres offering obstetric services in the Kilimanjaro region in north-eastern Tanzania. We anticipate that the results may suggest priority areas for improvement of neonatal care nationally and in sub-Saharan Africa generally.

\section{Methods}

The study was conducted in Kilimanjaro region of north-eastern Tanzania where data were collected from the northern zonal referral hospital and 13 referring peripheral hospitals by a purposive sampling technique. Of the 13 peripheral facilities included, 1 was the Kilimanjaro regional hospital, 4 were government-supported district hospitals, 6 were missionary-supported hospitals designated as district hospitals, and 2 were health centres with inpatient facilities servingurban Moshi's two largest wards. Each health care facility was visited unannounced and data were collected in a single day or at most over two days.

In each facility, staffing numbers were recorded from nationally standardized system i.e. Health Management Information Systems (HMIS), used for collection of data regarding health care workers in Tanzania; these data were verified in discussion with senior administrative staff in each hospital. Vital registration records and antenatal cards, records care and referral records were reviewed at each facility as well as at the zonal referral hospital from $26^{\text {th }}$ November, 2010 to $25^{\text {th }}$ April, 2011.

Maternity and paediatric wards were inspected for the presence of basic supplies and equipment using a preprepared standard check-list. In addition, health workers were requested, again using a standardized list, to estimate the availability of essential supplies in terms of the number of months per year a supply was typically available. In each hospital the senior nurse or clinician who was present in each of the relevant paediatric or maternity wards was asked to identify any neonate less than or equal to 30 days of age currently on the ward who had been admitted or retained post-delivery for a medical problem, including prematurity. In each case, the record of the last menstrual period (LMP) as recorded on the antenatal card was used to calculate gestational age. The case notes were inspected and standard informationwas extracted regarding the presence or absence of a list of 13 features judged to be essential to the record of a sick neonate, as shown in Figure 1. A record of Rh factorand blood group, syphilis and HIV screening, APGAR score and birth weight were extracted from all antenatal cards.

\section{Data Management and Analysis}

Data were single- entered in MS Access (Microsoft Corp, Redmond, VA). Original forms were consulted in the case of missing results or values out of expected ranges, and data were corrected as needed by the principal investigator

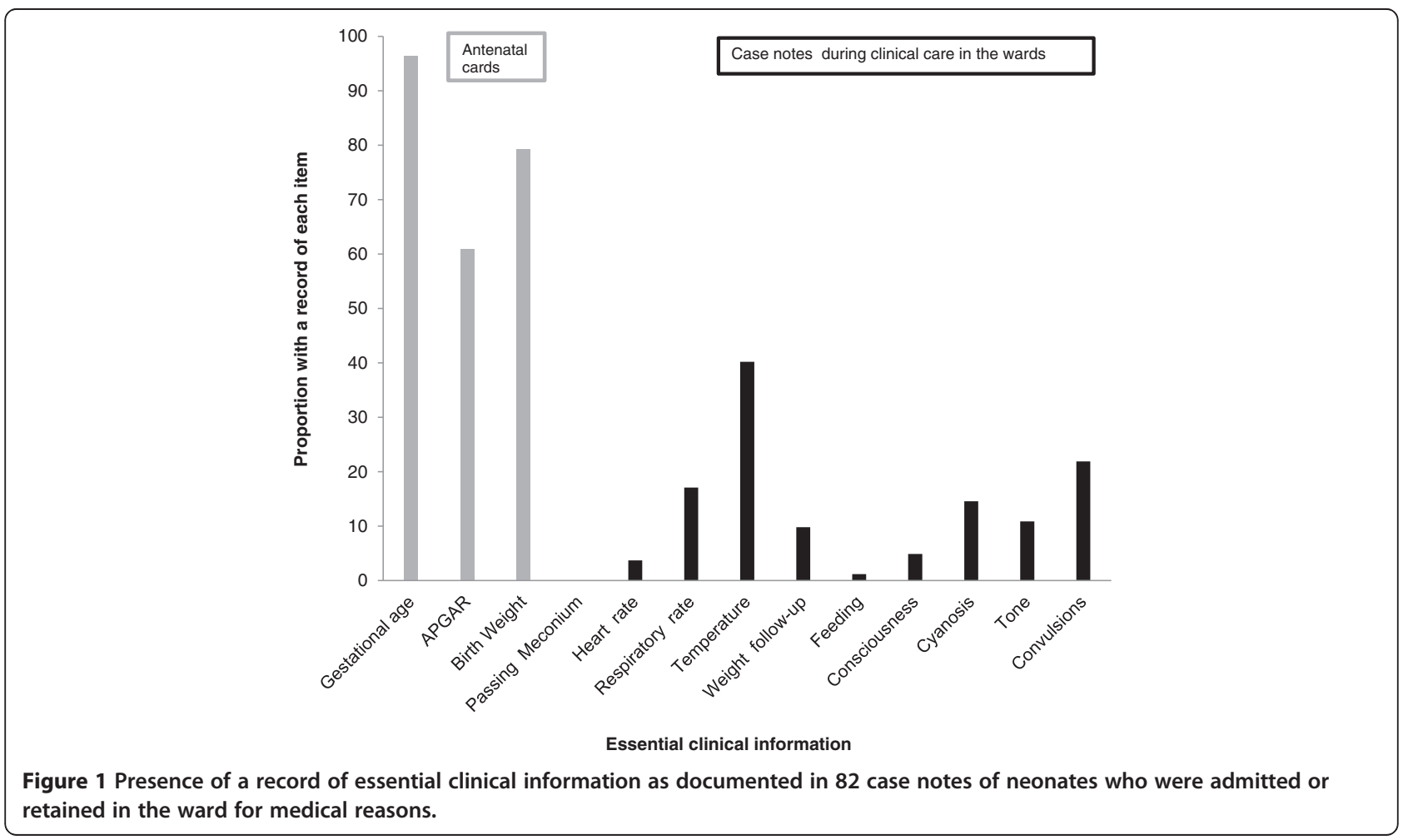


and the data manager. Data were analysed using Stata-10 (Stata Corp, TX, USA).

Staffing levels were assessed usingworkload indicators of staffing need (WISN). The expected number of health workers was found by dividing a yearly total time required to attend all neonates by total time available per health care worker (standardised by World Health Organization manual) [24]. The time required to attend one neonate was derived from the facility based neonatal admissions $[24,25]$.

Recordsof prescriptions for ampicillin, cloxacillin or gentamicin were extracted from case notes or prescription sheets and the dosages were assessed by reference to the WHO Emergency Triage Assessment and Treatment (ETAT) manual in the context of the neonate's weight.

\section{Ethics}

The study was approved by the Kilimanjaro Christian Medical University Ethics Committee. Written approval for the study was also received from the Kilimanjaro Regional Medical Officer. Written consent was obtained from the senior medical officer of each health facility for health workerinterviews, case notes assessments, checklists of supplies, photographs, and for results to be published.In addition, written consent was obtained from the guardians (mothers) of all enrolled neonates.

\section{Results}

Summary details of thereferral records from the 13 peripheral hospitals and the zonal referral hospital are shown in Table 1 and Figure 1. Eighty-two sick neonateswere enrolled from the 13 peripheralfacilities and their case notes examined. The mean (standard deviation, SD) age at time of case note review was 8.7 ( \pm 10.6) days.

The locations of neonatal care within each facility (i.e. maternal, paediatric, or special dedicated wards) are described in Table 2. The neonatal chart notes, or records of care, were found in disparate locations in the different facilities: in 3 facilities neonatal case notes were found in local school exercise books "daftari" as shown in Figure 2, 8 hospitals detailed neonatal care in the mothers' case notes, and 2 hospitals used standard medical files specific to the neonate. Antenatal cards were held by the mothers in 12 (92.3\%) of the 13 facilities and were located in facility-based records in one hospital.

\section{Data extracted from antenatal cards}

Antenatal cards of the all included neonates were assessed. The majority of mothers [59(71.9\%)] received antenatal care at facilities different from where they ultimately delivered their infants. Overall, 72 (88.0\%) mothershad attended an antenatal clinic at least three times (mean $2.95 \pm 1.3$ visits) during their pregnancy and all 82 enrolled neonates were born in health care facilities.
Table 1 Hospital data on neonatal births, deaths $1^{\text {st }}$ January to $31^{\text {st }}$ December 2010

\begin{tabular}{llllll}
\hline Facility code & $\begin{array}{l}\text { Facility } \\
\text { referrals }\end{array}$ & $\begin{array}{l}\text { Referrals } \\
\text { arrived at } \\
\text { a referral } \\
\text { hospital }\end{array}$ & $\begin{array}{l}\text { Live } \\
\text { births }\end{array}$ & Deaths & $\begin{array}{l}\text { Deaths / 1000 } \\
\text { live births }\end{array}$ \\
\hline F01 & 44 & 140 & 4,506 & 14 & 3.1 \\
F02 & 1 & 8 & 796 & 6 & 7.5 \\
F03 & 9 & 23 & 794 & 1 & 1.3 \\
F04 & 3 & 23 & 177 & 6 & 33.9 \\
F05 & 24 & 15 & 303 & 2 & 6.6 \\
F06 & 39 & 21 & 1,681 & 49 & 29.1 \\
F07 & 1 & 22 & 997 & 2 & 2.0 \\
F08 & 0 & 1 & 1,243 & 1 & 0.8 \\
F09 & 1 & 7 & 4,016 & 5 & 1.3 \\
F10 & 14 & 20 & 1,289 & 7 & 5.4 \\
F11 & 3 & 2 & 525 & 1 & 1.9 \\
F12 & 0 & 28 & 524 & 0 & 0 \\
F 13 & 6 & 38 & 732 & 0 & 0 \\
Peripheral & - & - & $\mathbf{1 7 , 5 8 3}$ & $\mathbf{9 4}$ & $\mathbf{5 . 3}$ \\
health & & & & & \\
facilities & & & $\mathbf{4 , 0 7 4}$ & $\mathbf{2 7 3}$ & $\mathbf{6 7 . 0 1}$ \\
Referral & N/A & $\mathbf{1 , 1 5 5}$ & & & \\
centre & & & & & \\
\hline
\end{tabular}

Records for Rh factor and blood group were present on antenatal cards in $39(47.6 \%)$ and $52(63.4 \%)$ cases respectively while syphilis or HIV screening was recorded on $59(71.9 \%)$ and 77 (93.1\%) antenatal cards respectively. Among 77 mothers who had received counselling, testing, and/or services for prevention of maternal to child transmission of HIV (PMTCT), 64 (83.0\%) were HIV negative, 12 (15.6\%) were HIV positive, and 1 (1.3\%) had declined testing.

Despite the $100 \%$ availability of APGAR score records in the delivery books at the included facilities, these records had been copied onto the antenatal cards in only $61.0 \%$ (50 records out of 82 ) cases. Birth weight records were available in 65 case notes $(79.3 \%)$ despite all the infants having been born in a health care facility. The median birth weight of neonates whose files were evaluated was 3000 grams with an interquartile range of 2600-3350 grams.

\section{Clinical data on neonates present on the ward}

Temperature was the most commonly recorded vital sign, found in $33(40.2 \%)$ case notes. Two thirds $(66.0 \%)$ of admitted neonates with records of temperature had a recording $\geq 38.0^{\circ} \mathrm{C}$. Admitting diagnoses as abstracted from the case notes the 82 enrolled neonates are shown in Figure 3; 40 of the neonates had more than one admitting diagnosis. Prematurity, defined as a gestation age 
Table 2 Staffing numbers and levels (by WISN) dedicated to neonatal care $1^{\text {st }}$ January to $31^{\text {st }}$ December 2010 in the peripheral facilities visited

\begin{tabular}{|c|c|c|c|c|c|c|c|c|c|c|}
\hline \multirow[t]{2}{*}{$\begin{array}{l}\text { Facility name } \\
\text { and code }\end{array}$} & \multirow[t]{2}{*}{ Location of neonatal care } & \multicolumn{3}{|c|}{$\begin{array}{l}\text { Clinicians available for } \\
\text { neonates }\end{array}$} & \multicolumn{3}{|c|}{$\begin{array}{l}\text { Nurses available for } \\
\text { neonates }\end{array}$} & \multicolumn{3}{|c|}{$\begin{array}{l}\text { Nurse attendants for } \\
\text { neonates }\end{array}$} \\
\hline & & Per Week & AM shift & WISN $^{1}$ & Per Week & AM shift & WISN $^{1}$ & Per Week & AM shift & WISN $^{1}$ \\
\hline F01 & Maternity & 4 & 1 & 0.19 & 15 & 3 & 3.98 & 2 & 2 & 0.35 \\
\hline F02 & Maternity & 2 & 2 & 0.55 & 10 & 2 & 6.01 & 2 & 1 & 2.01 \\
\hline F03 & Paediatric ward & 5 & 1 & 1.37 & 12 & 3 & 18.09 & 13 & 2 & 13.07 \\
\hline F04 & Maternity & 2 & 1 & 2.46 & 7 & 2 & 47.33 & 5 & 1 & 22.56 \\
\hline F05 & Maternity & 2 & 2 & 1.44 & 10 & 2 & 39.50 & 5 & 1 & 13.18 \\
\hline F06 & Maternity & 2 & 2 & 0.26 & 8 & 2 & 5.70 & 4 & 1 & 1.90 \\
\hline F07 & Maternity & 4 & 2 & 0.87 & 12 & 2 & 14.40 & 1 & 1 & 0.80 \\
\hline F08 & Maternity & 3 & 1 & 0.53 & 7 & 2 & 6.74 & 4 & 2 & 2.57 \\
\hline F09 & Maternity and Premature unit & 2 & 1 & 0.11 & 15 & 2 & 0.60 & 6 & 1 & 0.40 \\
\hline F10 & Maternity & 3 & 1 & 0.51 & 4 & 2 & 3.71 & 5 & 2 & 3.10 \\
\hline F11 & Maternity and Premature unit & 4 & 2 & 1.66 & 6 & 2 & 4.56 & 2 & 1 & 3.04 \\
\hline F12 & Maternity & 3 & 1 & 1.57 & 3 & 2 & 8.56 & 1 & 1 & 1.90 \\
\hline F13 & Labour ward & 1 & 1 & 0.37 & 3 & 2 & 6.13 & 3 & 2 & 4.09 \\
\hline
\end{tabular}

Footnote: WISN" stands for WHO devised "Workload indicator for staff need".

less than 36 weeks, was documented in only $11(9.0 \%)$ case notes while calculation from the antenatal card indicated that $36(45.6 \%)$ of 79 neonates with LMP data had a gestational age less than 36 weeks.

\section{Documentation and tracking referrals}

Records of referrals were made in Ministry of Health forms and discordance between this record and documented arrival at the zonal referral hospital is shown in Table 1. In no cases did the number of referred and received cases match, and in one case $100 \%$ of the received patients were unaccounted for at the referring institution.

\section{Laboratory investigations}

A record of full blood count was found in 4 (4.8\%) cases, and haemoglobin wasdocumentedin 6 (7.3\%) case notes. Nine (11\%) case notes had a record of blood sugar while 22 cases had a record of altered consciousness or convulsions that would normally be an indication to measure blood sugar. There were no laboratory investigations for blood culture or bilirubin as none of the facilities had capacity to perform these tests. Overall, only 8 (9.8\%) of case notes of the sick neonates in the district hospitals had record of any laboratory investigation.

\section{Prescriptions of oxygen, I.V fluids and Antibiotics}

There were 16 neonates who, according to the record of care, met indications for oxygen therapy, but only 6 (37.5\% of cases in which it was indicated) were documented to have received it. Only 8 neonates $(9.7 \%)$ had documentation of IV fluids, whereas we estimate that 24
(29.3\%) needed the intravenous fluid infusions due to clinical presentations of hypoglycaemia [glucose $<30$ $\mathrm{mg} / \mathrm{dl}]$ and/or a combination of high grade fever and inability to breast feed. Estimation of correct dosing of antimicrobial agents according to WHO guidelines is shown in Figure 4.

\section{Staffing of health workers}

Staff availability is presented in Table 2 . WISN for clinicians was 0.93 (ranging from 0.1 to 2.4), for nurses was 12.2 (ranging from 0.6 to 47.3), and for nurse attendants was 5.34 (ranging from 0.3 to 22.5 ).

\section{Supply of essential drugs and equipment}

Basic equipment was commonly available at the district hospitals with a relatively poor availability at the two heath centres (Figure 5). Nine out of 13 peripheral hospitals $(72.7 \%)$ in Kilimanjaro had visible stocks of essential drugs, oxygen and fluids to manage common neonatal infections and other disorders of mild severity such as transient tachypnoea of the new-born. These observations were subjectively well correlated with estimated availability in months per year reported by health workers interview (Figure 6).

\section{Discussion}

Care of neonates in Kilimanjaro region is characterized by poor documentation and a lack of common systems for documentation across facilities; in addition many of our findings suggest substandard care even within the context of available resources. These findings are apparently similar to those in Kenya [26] and those found among older 


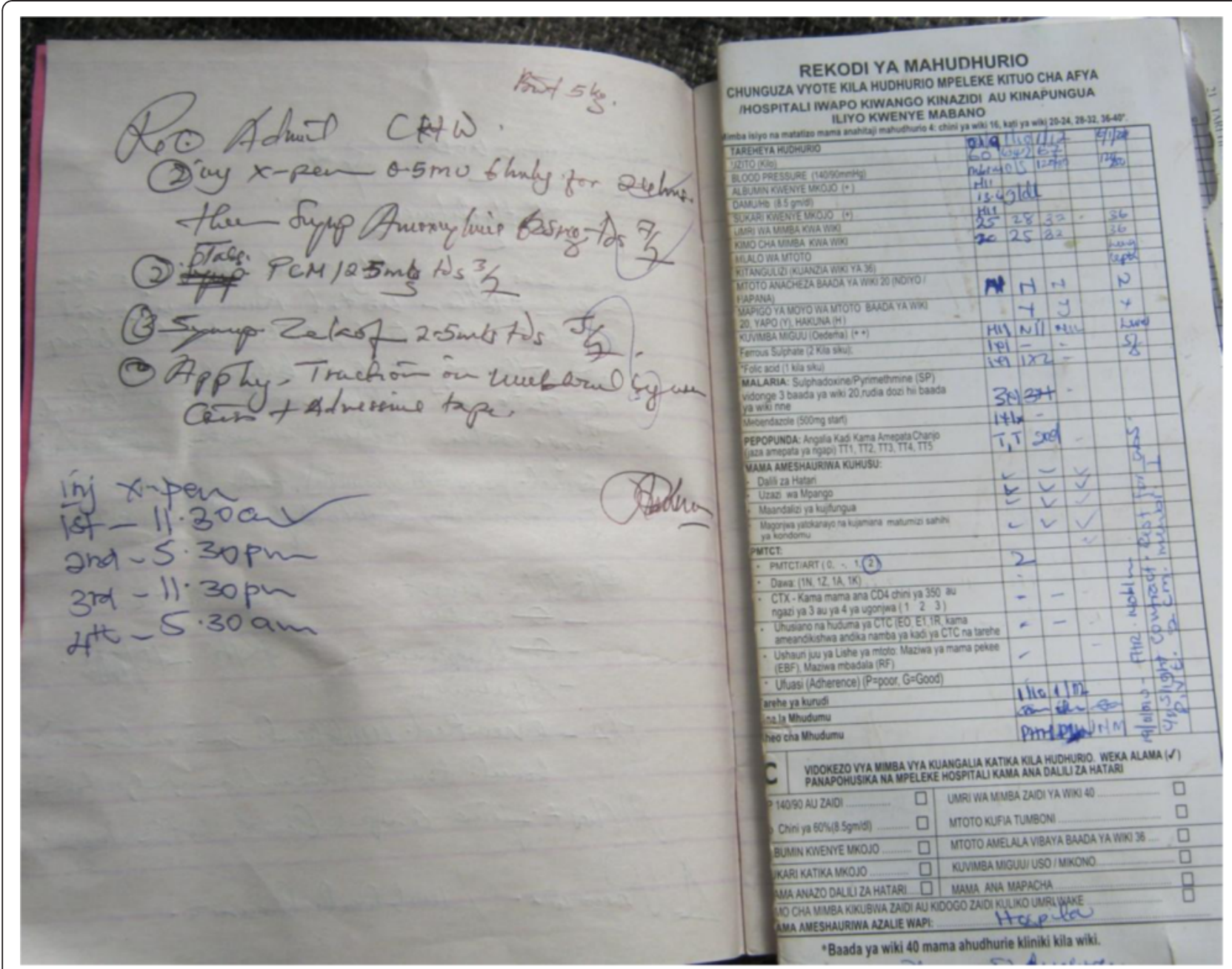

Figure 2 Records of care in Daftari. An example of primary school exercise books "Daftari" used in making records of neonatal care in one of the district hospital. On the right side is the sample of antenatal card we used to make assessment of records that are essential in neonatal care.

children in the same region [14]. While the neonatal mortality rates recorded at these facilities are lower than what might be expected given the conditions, the high mortality rate at the zonal referral hospital raises concern since many high risk women and neonates are transferred there. Substantial discrepancies noted between recorded referrals to thezonal referralhospital and records of received neonates at the zonal referral hospital demonstrate some of the challenges faced inhealth systems management, evaluation process and outcome of care.

One of our findings was the lack of a universal system for recording medical assessments and care provided to sick neonates, aside from the antenatal care card, which has very limited space for such evaluations. Neonatal care records were often difficult to locate and information provided within them was scant, with key diagnoses such as prematurity notably lacking in a substantial proportion of cases. Although absence of a record does not imply absence of examination, a poor record of care inevitably damages prospects for good continuity of care between staff and local systematic audits are difficult to perform. This is particularly important in neonatal care where clinical states change rapidly. Given the complexities that are unique to the care of neonates (high likelihood of hypothermia, hypoglycaemia, differences in "cut-off" for empiric antibiotics in the case of fever, need for different types of intravenous fluids), the availability of standard care forms which guide health care workers through the process of a typical neonatal admission could prove useful.

The fact that birth weight was missing from nearly one-fifth of universally filled antenatal cardsindicates poor motivation and/or oversight of clinical staff attending neonates delivered in health facilities. In addition to poor documentation, evidence of suboptimal care was prevalent. Incorrect dosing of antibiotics occurred in a substantial proportion of cases. Improbable diagnoses such as "gastroenteritis" were found on more than one occasion in chart notes, the latter being a highly unlikely 


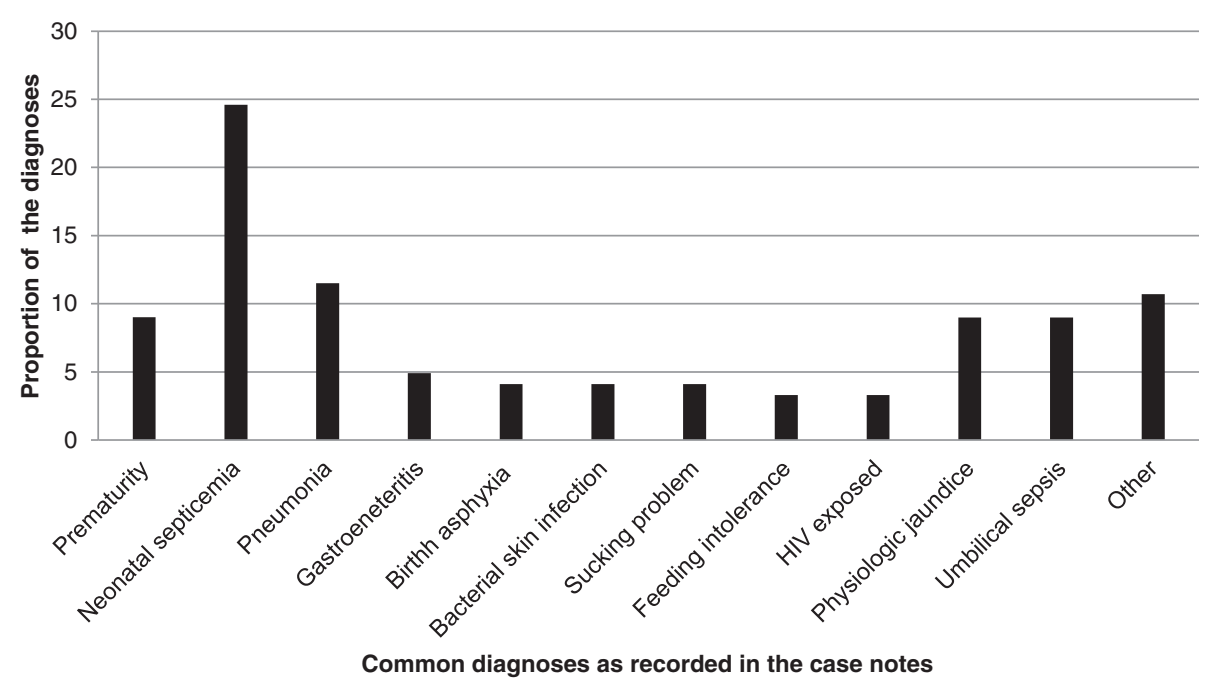

Figure 3 Diagnoses of admitted sick neonates present on the maternity or paediatric ward at the time of assessment.

diagnosis in neonates, especially in this setting where exclusive breastfeeding is almost universal through the neonatal period of one month; this is concerning since feeding intolerance and vomiting at this age could portend a much more serious diagnosis such as tracheaoesophageal fistula. The notably higher proportion of antenatal cards with HIV test results compared with other test results suggests that training, motivation, and efforts to make tests kits available on the ground can result in improved performance; there have been concerted efforts to promote prevention of maternal to child transmission in Kilimanjaro in recent years with highly successful results [27].

Missing laboratory tests, such as blood group and Rh factor in mothers and bilirubin in neonates is likely explained by lack of assay availability in many cases. The absence of anything beyond the most basic laboratory facilities at most of the hospitals in this study prevents

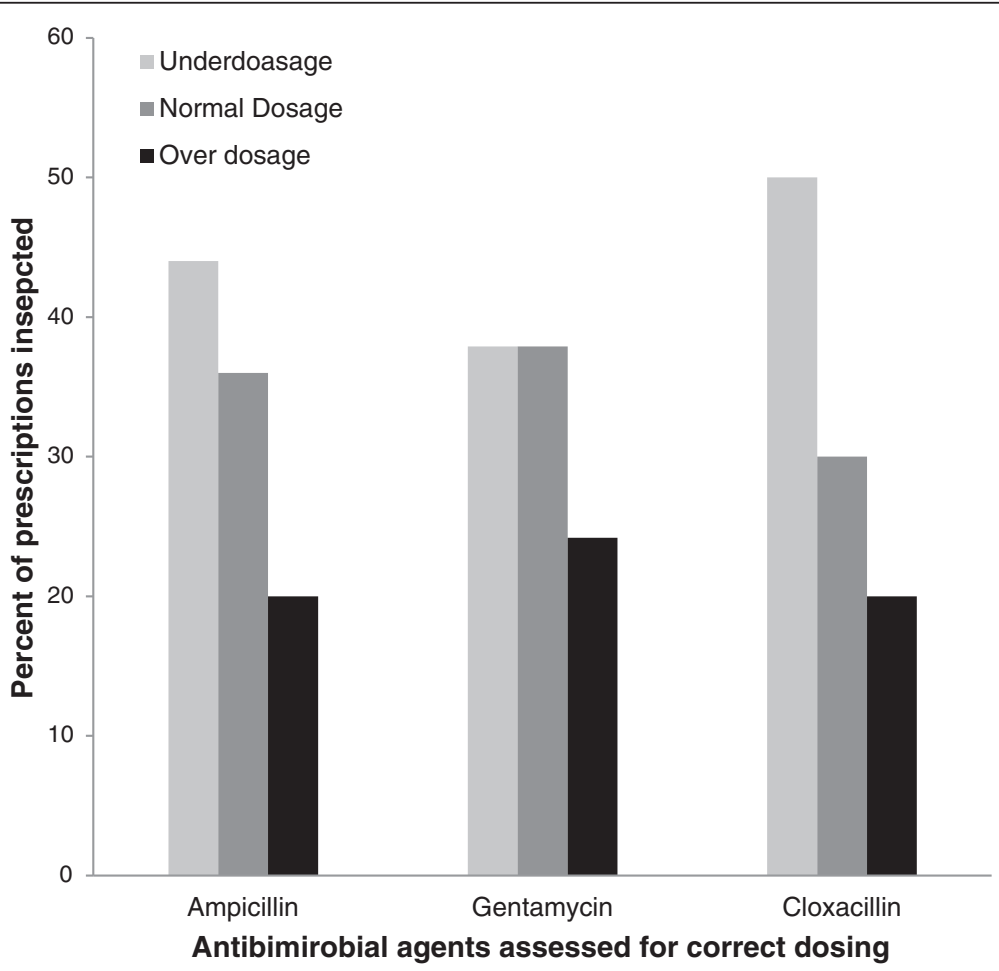

Figure 4 Assessment of prescriptions of doses given to sick neonates admitted in the district hospitals. 


\begin{tabular}{|c|c|c|c|c|c|c|c|c|c|c|c|c|c|c|c|}
\hline Facility & F1 & F2 & F3 & F4 & F5 & F6 & F7 & F8 & F9 & F10 & F11 & F12 & F13 & F14 & HW \\
\hline Resuscitation couch & & & & & & & & & & & & & & & Alw \\
\hline Oxygen Cylinder & & & & & & & & & & & & & & & Most \\
\hline Oxygen catheter & & & & & & & & & & & & & & & Alw \\
\hline Oxygen mask & & & & & & & & & & & & & & & Most \\
\hline Oxygen regulator & & & & & & & & & & & & & & & Most \\
\hline Heater & & & & & & & & & & & & & & & Most \\
\hline Ambulatory bag mask & & & & & & & & & & & & & & & Alw \\
\hline Incubator & & & & & & & & & & & & & & & Most \\
\hline Phototherapy for Billiru & & & & & & & & & & & & & & & Occa \\
\hline Burette & & & & & & & & & & & & & & & Most \\
\hline Neonatal cannulae & & & & & & & & & & & & & & & Com \\
\hline Suction Machine & & & & & & & & & & & & & & & Alw \\
\hline Torchfor & & & & & & & & & & & & & & & Occa \\
\hline Otoscope examination & & & & & & & & & & & & & & & Occa \\
\hline Nebulizer & & & & & & & & & & & & & & & Occa \\
\hline Thermometer & & & & & & & & & & & & & & & Alw \\
\hline Nasogastric tubes & & & & & & & & & & & & & & & Com \\
\hline Weighing scales & & & & & & & & & & & & & & & Alw \\
\hline Pulse Oxymeter & & & & & & & & & & & & & & & Occa \\
\hline
\end{tabular}

Key for the availability of essential equipments at the time of visit: Available att he time of visit Not available at the time of visit.

Key for the health workers opinions HW: Never available (Nev) $=0$ months, Occasionally available (Occa) $=1-3$ Months, Commonly available $(\mathrm{Com})=4$ - 6 months Most available (Most) $=7$ - 9 months, Always (Alw) $=10-12$ months

Figure 5 Availability of essential equipments as observed from the facility inspection on the day of survey and aggregated opinion of health staff on general availability of same items.

proper diagnosis and management of key frequently encountered conditions. Since prematurity and infections contributed to most of the hospitalizations, availability of blood culture systems and measurement of full blood picture are critical to appropriate management of these neonates, but most often unavailable [28-30].

However, we showed that even when supplies and diagnostics are available, they are not utilized appropriately, as in the case of glucometers, oxygen and intravenous fluids. The relative lack of expertise in neonatal care almost certainly contributes to these challenges; WISN for nurses tended to be high, but for clinicians was much lower, indicating a need for more specialized training in this area [31]. Similar lack of expertise in managing antenatal care as well as in managing sick children in hospital has previously been documented in Tanzania [14,32-35]; therefore it may not be surprising that neonatal care faces similar challenges.

While declines in child mortality rates in sub-Saharan Africa are encouraging, these declines are likely to stagnate if quality of neonatal care is not addressed. Achieving MDG 4 remains a challenging task in rural Tanzania, $[36,37]$ and sub-Saharan Africa [38]. Over the last 5 years declines in infant and child mortality rates have stagnated $[39,40]$. Our data demonstrate that improvements will need to cover several areas, but that better care may be delivered even within the confines of currently available staff and equipment if there are 


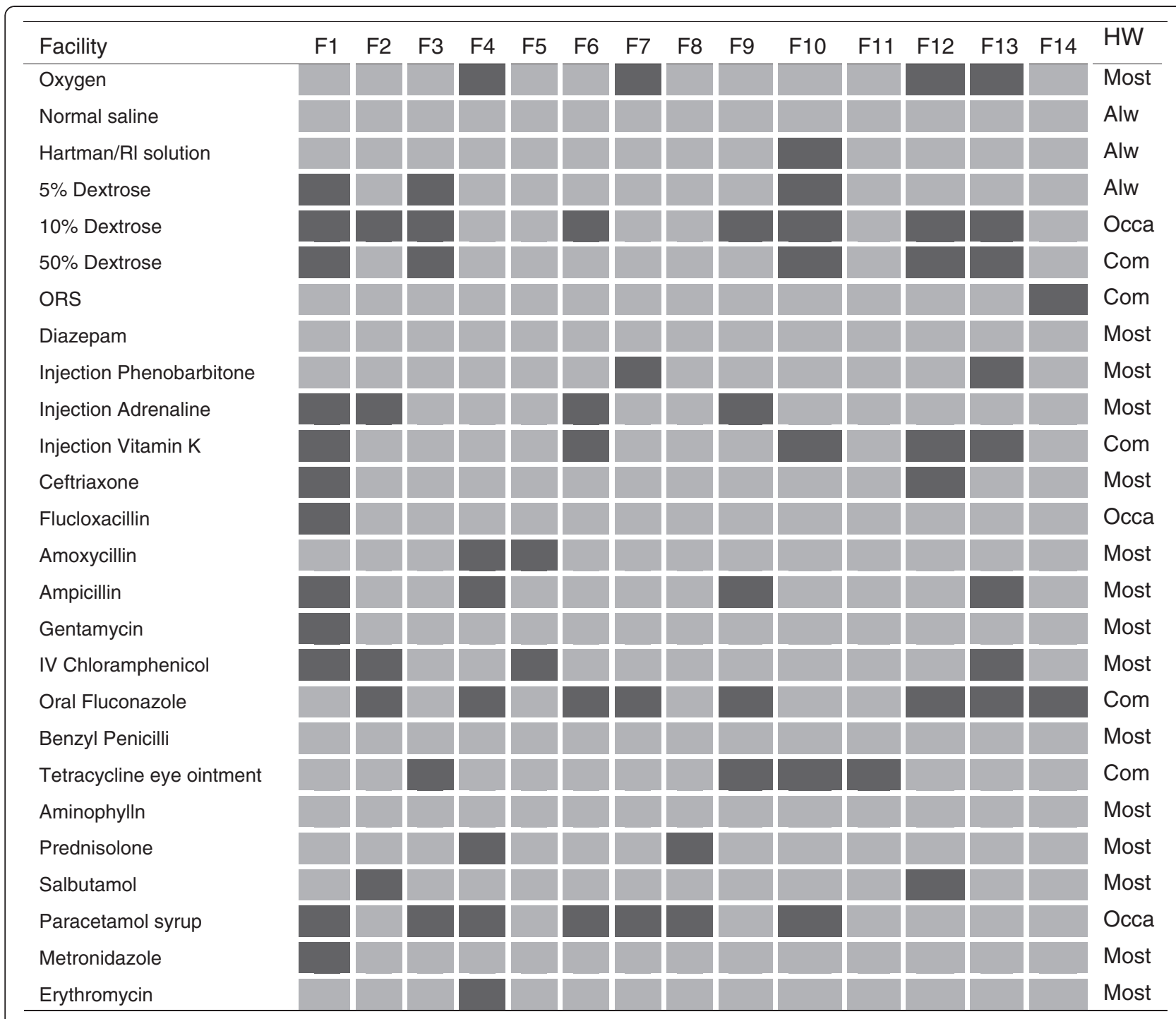

Key for the availability of essential drugs and infusions at the time of visit: Available at the time of visit Not available at the time of visit.

Key for the health workers opinions HW: Never available (Nev) $=0$ months, Occasionally available (Occa) $=1-3$ Months, Commonly available $(\mathrm{Com})=4-6$ months Most available (Most) $=7$ - 9 months, Always $($ Alw $)=10-12$ months

Figure 6 Availability of essential drugs and infusions as observed from the facility inspection on the day of survey and aggregated opinion of health staff on general availability of same items.

improvements in training, motivation and standard operating procedures/guidelines to address key issues in neonatal care.

\section{Limitations}

Our study had several limitations. First, sampling of facilities was not random, though it included the entire group of district and designated district hospitals in the region. Second, the limitations of tools to measure the quality of care are well known; direct observation is likely to bias performance (the Hawthorne effect) and a record of care is not the same as care itself. That having been said, the fact that facility awareness and patient enrolment took place typically on the same day, bias related to altering quality of care because of direct observation is substantially reduced, which is a strength of the study. Third, resource constraints did not allow for a longer period of observation that would have produced larger numbers and more robust findings, however our data comprehensively assessed the most important 
aspects of care for common conditions found in neonates and the equipment available at each participating facility. Finally, this study did not evaluate the care of healthy neonates with no identified problems and did include neonates born at home or in smaller health care facilities, such as dispensaries. We assumed infants with high-levelcare needs were referred to the zonal referral hospital; the infants in this study reflected a level of mild-to-moderate illness severity for which we expected that their care generally should be able to be managed at a district hospital level.

\section{Conclusion}

Documentation of care for sick neonates hospitalized in peripheral health facilities in Kilimanjaro demonstrates significant deficits in areas which could have major health implications, not only for infant outcomes but also for program assessment and planning. Lack of regular auditing, few highly trained staff,and low availability of equipment and laboratory facilities all contribute to these challenges.

\section{Recommendations}

There is a need to enhance neonatal-specific training for hospital staff, and introduce a standard clinical record form for sick neonates admitted to hospital facilities.

\section{Competing interests}

The study was funded by the Tanzanian Ministry of Health and Social Welfare as the first authors' prerequisite study for the completion of MSc Clinical Research at Kilimanjaro Christian Medical University. Additional working support and expertise was given by volunteers who were medical personnel and university students with data entry experience. There have been noreimbursements, fees, funding, nor salary from any organization that depends on or influence the results of this study. The author does not hold any stocks or shares in an organization that may in any way might be affected by this publication.

\section{Authors' contribution}

BM developed a concept of research work, proposal development, data collection, database development, analysis, report writing and writing of the manuscript. HR was the external supervisor and the organiser who provided technical guidance of proposal development, data collection and analysis. ER assisted in the planning of data extraction tools and in writing of the manuscript. All authors read and approved the final manuscript.

\section{Authors' information \\ $\mathrm{BM}$ is a Tanzanian medical doctor and clinical researcher at Kilimanjaro Clinical Research Institute of Kilimanjaro Christian Medical Centre, Moshi Tanzania. HR is faculty at the London school of Hygiene and Tropical Medicine and he is a project leader at the Joint Malaria Programme in Moshi, Tanzania. He was the organiser and the overall supervisor for proposal writing and report designs. ER is a paediatrician, internist and researcher who directs collaborative research programs between Duke University and Kilimanjaro Christian Medical Centre.}

\section{Acknowledgement}

Thanks to Prof Bernard C.J Hammel, Prof Raimos Olomi, Dr Seif Shekalaghe, Dr Jaffu Chilongola and John George Mrema for technical assistance. To Joshua Melnick from University of Georgia, Athens, U.S.A, Flavian Masokoto from Uru Mawela Parish of Moshi, Sarah Ward from Bowdoin Collegeof U.S. A., Laurens Maarten Moeliker and Robert Gerard Leicher from the Netherlands, Anne Eckleof from Stockholm Sweden, Patric Toalson, Sung Bo Yung, Tamara Russel, Laura Thorpe, Elke Wasdovich from Lilly pharmaceutical company who volunteered to collect and enter data in our database. Many thanks again to Ibptisam Shaabal, a medical student from Malaysia for the final data collection and data entry. Last but not least to the health workers and the mothers of sick neonates admitted in the year 2010 and 2011.

\section{Author details}

${ }^{1}$ Kilimanjaro Clinical Research Institute, P.O Box 2236, Moshi, Tanzania. ${ }^{2}$ Duke University Dept. of Medicine; Division of Infectious Disease, Kilimanjaro Christian Medical Centre-Duke University Collaboration, P.O Box 3010, Moshi, Tanzania. ${ }^{3}$ London school of Hygiene and Tropical Medicine, Disease Control Dept, Faculty of Infectious and Tropical Disease, London School of Hygiene and Tropical Medicine, Keppel St, London WCIE 7HT, UK.

Received: 8 July 2012 Accepted: 14 November 2012

Published: 21 November 2012

\section{References}

1. World Health Organization: Neonatal and Perinatal Mortality: Country, Regional and Global Estimates. In World Health Organization Report 2006. Geneva: World Health Organization; 2006.

2. Liu L, Johnson HL, Cousens S, Perin J, Scott S, Lawn JE, Rudan I, Campbell H, Cibulskis R, Li M, et al: Global, regional, and national causes of child mortality: an updated systematic analysis for 2010 with time trends since 2000. Lancet 2012, 379(9832):2151-2161

3. Lawn JE, Cousens S, Darmstadt GL, Paul V, Martines J: Why are 4 million newborn babies dying every year? Lancet 2004, 364(9450):2020.

4. Belizan JM, McClure EM, Goudar SS, Pasha O, Esamai F, Patel A, Chomba E, Garces A, Wright LL, Koso-Thomas M, et al: Neonatal Death in Low- to Middle-Income Countries: A Global Network Study. Am J Perinatol 2012, 100(8):2097-2105.

5. Manji K: Situation analysis of newborn health in Tanzania: Current situation, existing plans and strategic next steps for newborn health. Edited by Save the Children. Dar es Salaam: Ministry of Health and Social Welfare; 2009.

6. World Health Organization: WHO report calls for new approach to save lives of mothers and children. Edited by center WM. Geneva: World Health Organization; 2005

7. Lawn JE: Opportunities for Africa's Newborns: practical data, policy and programmatic support for newborn care in Africa. Cape Town: PMNCH, Save the Children, UNFPA, UNICEF, USAID, WHO; 2006.

8. Ahman E, Zupan J: Neonatal and perinatal mortality: country, regional and global estimates. Geneva: World Health Organization, Department of Making Pregnancy Safer; 2004:4-14

9. Rajaratnam JK, Marcus JR, Flaxman AD, Wang H, Levin-Rector A, Dwyer L, Costa M, Lopez AD, Murray CJ: Neonatal, postneonatal, childhood, and under-5 mortality for 187 countries, 1970-2010: a systematic analysis of progress towards Millennium Development Goal 4. Lancet 2010, 375 (9730):1988-2008.

10. UNICEF: United Republic of Tanzania: Statistics. New York: UNICEF; 2009 Accessed $3^{\text {rd }}$ September 2010, http://www.unicef.org/infobycountry/ tanzania_statistics.html.

11. Mrisho M, Schellenberg D, Manzi F, Tanner M, Mshinda H, Shirima K, Msambichaka B, Abdulla S, Schellenberg JA: Neonatal deaths in rural southern Tanzania: care-seeking and causes of death. ISRN pediatrics 2012, 2012:953401.

12. Duke T: Problem-solving clinical audit: a vehicle for improving the quality of hospital care. Papua and New Guinea medical journal 2003, 46(3-4):109-112.

13. English M, Esamai F, Wasunna A, Were F, Ogutu B, Wamae A, Snow RW Peshu N: Assessment of inpatient paediatric care in first referral level hospitals in 13 districts in Kenya. Lancet 2004, 363(9425):1948-1953.

14. Reyburn H, Mwakasungula E, Chonya S, Mtei F, Bygbjerg I, Poulsen A, Olomi R: Clinical assessment and treatment in paediatric wards in the north-east of the United Republic of Tanzania. Bulletin of the World Health Organization 2008, 86(2):132-139.

15. Gaise SK: Mortality, Socio-Economic Differentials and Modernisation in Africa in Population Dynamics: Fertility and Mortality in Africa Proceedings of the Expert Group Meeting on Fertility and Mortality Levels and Trends in Africa and their Policy Implications. Monrovia: United Nations Economic Commission for Africa; 1979:441-463.

16. Mott LF: Infant Mortality in Kenya: Evidence from the Kenya Fertility Survey. In World Fertility Survey Scientific Report. Voorburg: International Statistical Institute; 1982 
17. Newman J: Nutrition, Disease and Mortality in Young Children. In Population Dynamics: Fertility and Mortality in Africa In: proceedings of the Expert Group Meeting on Fertility and Mortality Levels and Trends in Africa and their Policy Implications. Liberia: UNECA; 1979:513-526.

18. Acolet D: Quality of neonatal care and outcome. Archives of disease in childhood Fetal and neonatal edition 2008, 93(1):F69-F73.

19. Kidanto HL, Massawe SN, Nystrom L, Lindmark G: Analysis of perinatal mortality at a teaching hospital in Dar es Salaam, Tanzania, 1999-2003. Afr J Reprod Heal 2006, 10(2):72-80.

20. Iriya N, Manji KP, Mbise RL: Verbal autopsy in establishing cause of perinatal death. East African medical journal 2002, 79(2):82-84

21. Klingenberg C, Olomi R, Oneko M, Sam N, Langeland N: Neonatal morbidity and mortality in a Tanzanian tertiary care referral hospital. Ann Trop Paediatr 2003, 23(4):293-299.

22. Hinderaker SG, Olsen BE, Bergsjo PB, Gasheka P, Lie RT, Havnen J, Kvale G: Avoidable stillbirths and neonatal deaths in rural Tanzania. BJOG: an international journal of obstetrics and gynaecology 2003, 110(6):616-623.

23. Kidanto HL, Mogren I, van Roosmalen J, Thomas AN, Massawe SN, Nystrom $\mathrm{L}$, Lindmark G: Introduction of a qualitative perinatal audit at Muhimbili National Hospital, Dar es Salaam, Tanzania. BMC pregnancy and childbirth 2009, 9:45.

24. World Health Organization: Workload indicators of staff need, Users manual. Geneva: World Health Organization; 2010.

25. Nyamtema AS, Urassa DP, Massawe S, Massawe A, Lindmark G, Van Rosmalen J: Staffing needs for quality perinatal care in Tanzania. Afr J Reprod Heal 2008, 12(3):113-124.

26. Opondo C, Ntoburi S, Wagai J, Wafula J, Wasunna A, Were F, Wamae A, Migiro S, Irimu G, English M: Are hospitals prepared to support newborn survival? - An evaluation of eight first-referral level hospitals in Kenya. Tropical medicine \& international health: TM \& IH 2009, 14(10):1165-1172.

27. Opiyo N, English M: In-service training for health professionals to improve care of the seriously ill newborn or child in low and middleincome countries (Review). Cochrane database of systematic reviews 2010 14(4):CD007071.

28. English M, Ntoburi S, Wagai J, Mbindyo P, Opiyo N, Ayieko P, Opondo C, Migiro S, Wamae A, Irimu G: An intervention to improve paediatric and newborn care in Kenyan district hospitals: understanding the context. Implementation science: IS 2009, 4:42.

29. Dow DE, Schimana W, Feng S, Shayo A, Bartlett JA, Massambu CG, Cunningham CK, Buchanan AM: PMTCT performance among HIV-infected infants in Tanzania. Washington, DC: The XIX International AIDS Conference. [Accepted for presentation at the XIX International AIDS Conference; July 22-27]; 2012.

30. Petti CA, Polage CR, Quinn TC, Ronald AR, Sande MA: Laboratory medicine in Africa: a barrier to effective health care. Clinical infectious diseases: an official publication of the Infectious Diseases Society of America 2006, 42(3):377-382

31. Polage CR, Bedu-Addo G, Owusu-Ofori A, Frimpong E, Lloyd W, Zurcher E, Hale D, Petti CA: Laboratory use in Ghana: physician perception and practice. Am J Trop Med Hyg 2006, 75(3):526-531.

32. Petti CA, Polage CR, Hillyard DR: Screening laboratory requests. Emerg Infect Dis 2006, 12(11):1792-1793.

33. Anyangwe SC, Mtonga C: Inequities in the global health workforce: the greatest impediment to health in sub-Saharan Africa. International journal of environmental research and public health 2007, 4(2):93-100.

34. Gross K, Armstrong Schellenberg J, Kessy F, Pfeiffer C, Obrist B: Antenatal care in practice: an exploratory study in antenatal care clinics in the Kilombero Valley, south-eastern Tanzania. BMC pregnancy and childbirth 2011, 11:36

35. Gross K, Alba S, Glass TR, Armstrong Schellenberg J, Obrist B: Timing of antenatal care for adolescent and adult pregnant women in southeastern Tanzania. BMC pregnancy and childbirth 2012, 12(1):16.

36. Sarker M, Schmid G, Larsson E, Kirenga S, De Allegri M, Neuhann F, Mbunda T, Lekule I, Muller O: Quality of antenatal care in rural southern Tanzania: a reality check. BMC research notes 2010, 3:209.

37. Pembe AB, Carlstedt A, Urassa DP, Lindmark G, Nystrom L, Darj E: Quality of antenatal care in rural Tanzania: counselling on pregnancy danger signs. BMC pregnancy and childbirth 2010, 10:35.

38. Lozano R, Wang H, Foreman KJ, Rajaratnam JK, Naghavi M, Marcus JR, DwyerLindgren L, Lofgren KT, Phillips D, Atkinson C, et al: Progress towards
Millennium Development Goals 4 and 5 on maternal and child mortality: an updated systematic analysis. Lancet 2011, 378(9797):1139-1165.

39. United Nations Development Programme, UNDP Tanzania: Mid-Way Evaluation: 2000-2008. In Millennium development goal progress report. Dar es Salaam: UNDP. 2009. Accessed $28^{\text {th }}$ February 2010. http://www.tz.undp.org/ mdgs_goal4.html.

40. Bhutta ZA, Chopra M, Axelson H, Berman P, Boerma T, Bryce J, Bustreo F, Cavagnero E, Cometto G, Daelmans B, et al: Countdown to 2015 decade report (2000-10): taking stock of maternal, newborn, and child survival. Lancet 2010, 375(9730):2032-2044.

doi:10.1186/1471-2431-12-182

Cite this article as: Mbwele et al:: A rapid assessment of the quality of neonatal healthcare in Kilimanjaro region, northeast Tanzania. BMC Pediatrics 2012 12:182.

\section{Submit your next manuscript to BioMed Central and take full advantage of:}

- Convenient online submission

- Thorough peer review

- No space constraints or color figure charges

- Immediate publication on acceptance

- Inclusion in PubMed, CAS, Scopus and Google Scholar

- Research which is freely available for redistribution 